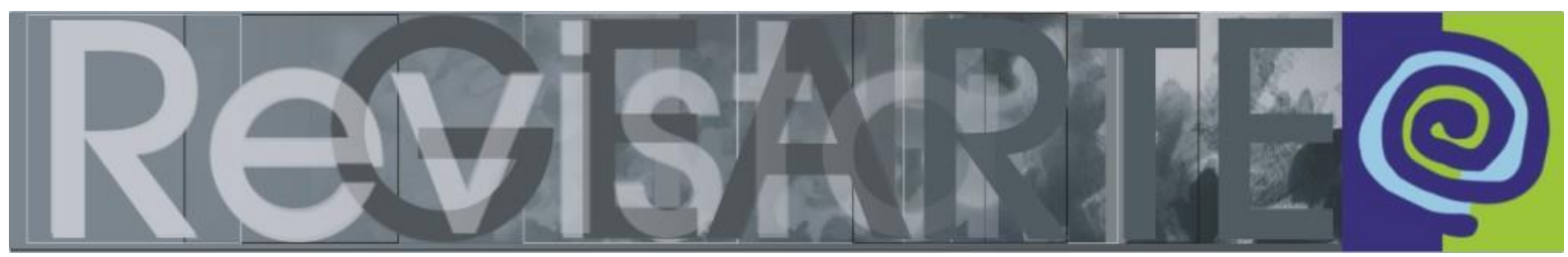

e-ISSN 2357-9854

\title{
Ensino de cinema na educação básica: aspectos legais
}

\author{
Diogo José de Moraes Lopes Barbosa (Universidade Federal \\ da Paraíba - UFPB, João Pessoa/PB, Brasil) \\ Guilherme Barbosa Schulze (Universidade Federal da \\ Paraíba - UFPB, João Pessoa/PB, Brasil)
}

\begin{abstract}
RESUMO - Ensino de cinema na educação básica: aspectos legais - Neste artigo, mostraremos uma pesquisa sobre a presença do cinema na escola de educação formal básica a partir da vigência de diversas leis. $O$ ensino de cinema na educação pode se dar por meio de muitas formas. Ele pode acontecer pela disciplina de arte, tendo em vista que o cinema, sobretudo, em nossos estudos, pode ser contemplado como uma linguagem artística, além das outras já existentes nessa disciplina (o teatro, a dança, as artes visuais e a música). Mas ele também pode ser visto na escola a partir da lei 13.006 de 2014 que institui a exibição de pelos menos duas horas de filmes nacionais por mês. Desta forma, pudemos concluir que a arte cinematográfica não apenas é necessária do ponto de vista pedagógico para o crescimento do educando enquanto indivíduo, mas também é uma área do conhecimento que deve, juridicamente, ser vista na escola.
\end{abstract}

Palavras-chave

Cinema e Educação. Ensino de Arte. Leis da educação.

ABSTRACT - The teaching of cinema in Basic Education: legal aspects - In this article, we will present a research about the presence of the cinema in the basic formal school of education from the validity of several laws. The teaching of cinema in education can happen in many ways. It can happen through the discipline of art, since cinema, especially in our studies, can be contemplated as an artistic language, besides the others already existing in this discipline (theater, dance, visual arts and music). But it can also be seen in school from the law 13.006 of 2014 which institutes movie screening of at least two hours of national films per month. In this way, we could conclude that cinematographic art is not only pedagogically necessary for the growth of the student as an individual, but also an area of knowledge that must, legally, be seen in school.

Keywords

Cinema and Education. Teaching Art. Education Laws.

\section{Introdução}

Ensinar cinema na escola significa encontrar, experimentar, transmitir uma forma de arte, segundo o pensamento do professor e crítico francês de cinema, Alain Bergala (2008). Ele foi responsável pela implantação do ensino de cinema nas escolas francesas quando o ministério da educação foi gerindo por Jack Lang no início dos anos 2000. Bergala, então, criou uma série de estratégias para que o cinema se tornasse algo presente nas escolas. Ele incentivou a criação de cinematecas e 
DVDtecas nas instituições, estimulou a formação de profissionais, assim como os estudos e as pesquisas sobre esse tema.

Não podemos dizer ao certo até que ponto tais práticas na França incentivaram ações parecidas em outros países. No Brasil, por exemplo, o cinema é algo que já esteve próximo à educação desde as primeiras décadas de seu surgimento. Temos como exemplo, a criação do INCE (Instituto Nacional de Cinema Educativo) pelas mãos do então presidente da república, Getúlio Vargas, no ano de 1937 como afirma a pesquisadora Rosália Duarte (2009, p.29). Antes disso, no ano de 1932, Vargas assinou um decreto (ํㅡ 21.240/1932) sancionando uma série de questões acerca do cinema nacional, dentre elas, a obrigatoriedade de um filme educativo em cada conjunto de obras em cartaz nas salas de exibição. Estes foram os primeiros passos da junção cinema/educação em nosso país. Outros surgiram até culminar na lei 13.006, que trata da obrigatoriedade de exibição de filmes nas escolas, da qual trataremos mais à frente nesse artigo.

\section{A arte na escola}

Quando Alain Bergala vislumbrou a possibilidade de o cinema ser algo presente nas instituições de educação na França, ele pensou nele enquanto arte. Isto não significa que a arte não fazia parte das escolas em seu país. A disciplina de Educação Artística já estava presente no currículo francês, da mesma forma que acontece no Brasil.

Em nosso país, diversas linguagens artísticas devem fazer parte do nosso currículo, são elas as artes cênicas, as artes visuais e a música. O ensino dessas formas de arte no Brasil é, inclusive, respaldado juridicamente. Segundo a Lei de Diretrizes e Bases da Educação Brasileira (LDB), as artes visuais, a dança, a música e o teatro são as linguagens que constituirão o Componente Curricular Arte (Lei no 13.278/2016). Dessa forma, "[...] a disciplina Arte deverá garantir que os alunos conheçam e vivenciem aspectos técnicos, inventivos, representacionais e expressivos em música, artes visuais, desenho, teatro, dança, artes audiovisuais" (FERRAZ e FUSARI, 2010, p.22). Apesar do cinema não estar explicitamente presente enquanto 
uma linguagem específica como o teatro ou a dança, Ferraz e Fusari entendem que o cinema pertence à disciplina de Arte enquanto expressão artística audiovisual.

A primeira sanção da lei em questão, a 13.278, data de 1996. Como expõe Ana Mae Barbosa:

\begin{abstract}
A aprendizagem de Arte é obrigatória pela LDB no Ensino Fundamental e no Ensino Médio. Contudo, algumas escolas estão incluindo a Arte apenas numa das séries de cada um desses níveis porque a LDB não explicitou que este ensino é obrigatório em todas as séries. No caso do Ensino Médio, algumas Secretarias de Educação estão usando o subterfúgio da interdisciplinaridade, e incluem todas as Artes na disciplina de Literatura, ficando tudo a cargo do professor de Língua e Literatura. Essa é uma forma de eliminar as outras linguagens da Arte, fazendo prevalecer o espírito educacional hierárquico da importância suprema da linguagem verbal e consequente desprezo pela linguagem visual. $(2008$, p.13).
\end{abstract}

Assim, a LDB tornou obrigatório o ensino de artes na escola, mas não deixou claro quais níveis da educação deveriam ter acesso a este conhecimento ou quais linguagens exatamente deveriam ou não ser apresentadas. Isto acabou por privilegiar algumas linguagens em detrimento de outras. Se o professor de arte da escola tem uma formação em artes visuais, dificilmente ele irá ensinar música para as crianças e adolescentes. Sobretudo, se compreendermos que este professor teve nenhuma, ou muito pouca formação na linguagem da música. Para que um professor tenha um entendimento amplo e suficiente das quatro áreas (teatro, dança, artes visuais e música), sua formação deverá ser bem maior e mais duradora do que a obtida atualmente nas faculdades e universidades.

Desta forma, seria natural e compressível que um professor de arte não tenha uma atuação excelente em todas as linguagens artísticas por igual, ou seja, desempenhe uma função polivalente satisfatória no ensino da disciplina em questão, como sempre foi esperado. Apesar disso, a lei 13.278 atualizada enfatiza que as quatro áreas artísticas pertencem ao Componente Curricular Arte, sem haver qualquer hierarquia entre elas. Assim, hoje, segundo a atualização desta lei, o aluno deve ter acesso aos conteúdos e conhecimentos das quatro áreas artísticas já apresentadas. Apesar disso, a lei ainda não estabelece que cada linguagem da arte deva ser ensinada por professores de suas áreas artísticas específicas, reforçando ainda mais as já mencionadas práticas de polivalência. Ou seja, um professor com formação em 
teatro deve lecionar obrigatoriamente as quatro linguagens, mesmo sem ter um conhecimento suficientemente mínimo sobre elas.

Ainda recentemente, a Lei 13.415 de 16 de fevereiro de 2017, trouxe novas questões sobre o ensino de artes, sobretudo, no Ensino Médio. Ela surge com certas controversas sobre as práticas docentes, que podem recair na disciplina de Arte. Isto porque ela insere a figura do professor com notório saber. Na verdade, este profissional, segundo esta lei, só poderá atuar na área referente à formação técnica e profissional. Desta forma, a disciplina de Arte no ensino médio, se a lei for interpretada de forma correta, deverá continuar a ser lecionada por um professor licenciado em um dos cursos de arte. Mesmo tendo havido muitas confusões e possíveis propostas de retirada da disciplina de Arte do currículo escolar, sua presença permanece obrigatória na educação básica como é explicitado no parágrafo $2^{\circ}$ do artigo 26 .

\section{O cinema na escola}

Em meio a todas essas leis, o cinema não é visto como uma linguagem artística específica, ou seja, ele não é enquadrado como um subcomponente curricular como acontece com as outras quatro linguagens. Contudo, a sua presença na educação formal básica pode ser vista por outros vieses. De acordo com os Parâmetros Curriculares Nacionais (PCN) de Arte, por exemplo, a arte cinematográfica deve ser vista dentro do programa, mais especificamente, de artes visuais:

As artes visuais, além das formas tradicionais (pintura, escultura, desenho, gravura, arquitetura, artefato, desenho industrial), incluem outras modalidades que resultam dos avanços tecnológicos e transformações estéticas a partir da modernidade (fotografia, artes gráficas, cinema, televisão, vídeo, computação, performance) (BRASIL, 1997, p.45, grifo nosso).

Neste caso, o ensino dos conteúdos do cinema enquanto arte, contemplando seus aspectos estéticos, técnicos, culturais, sociais, faz parte, ou ao menos deveria, da disciplina de artes visuais.

Ainda de acordo com a LDB, em 26 de junho de 2014, foi sancionada a lei que torna obrigatória a exibição aos alunos de, no mínimo, duas horas de filmes de 
produção nacional. Desta forma, o cinema se apresenta como Componente Curricular Complementar integrado à proposta pedagógica da escola (Lei no 13.006/2014).

\begin{abstract}
O projeto percorreu uma longa estrada, cercado de resistências que foram desaparecendo nos últimos passos. Um dos debates foi se a exibição de filmes deveria ser parte do currículo complementar integrado à proposta pedagógica da escola ou como conteúdo programático da disciplina Arte, em que a exibição de filmes nacionais seria apenas um indicativo e não uma obrigatoriedade. Em 5 de junho de 2014, um substitutivo relatado pelo senador Cyro Miranda, que modificava a matéria da Lei nessa direção, é rejeitado. Com os cumprimentos ao autor da Lei original, Cristovam Buarque, o Projeto 185 de 2008 vai à sanção em sua primeira redação: "A exibição de filmes de produção nacional constituirá componente curricular complementar integrado à proposta pedagógica da escola, sendo a sua exibição obrigatória por no mínimo duas horas mensais" (FRESQUET; MIGLIORIN In FRESQUET, 2015, p.05)
\end{abstract}

Essa nova lei foi sem dúvida um grande passo para a inserção do cinema na educação formal, contudo, muitas questões ainda precisam ser discutidas e, sobretudo, compreendidas. De acordo com a lei em questão, por exemplo, a responsabilidade de conduzir essas experiências, no caso das exibições, não fica clara. O documento não explicita quem deve mediar as sessões de cinema e mesmo, quais objetivos pedagógicos devem ser alcançados. O filme, neste caso, deve ser visto enquanto obra artística onde o estudo dos seus códigos é priorizado ou ele irá funcionar como instrumento facilitador para o conteúdo de outras disciplinas ou temas diversos?

Já o ensino do cinema, dentro da disciplina de Arte, deve ficar a cargo do professor de arte. Contudo, podemos expor algumas dificuldades acerca de tais práticas: problemas de ordem estruturais como a ausência de espaços físicos adequados (salas amplas, arejadas e ao mesmo tempo, escuras que possam contemplar projeções de filmes); a falta de equipamentos que possam dar suporte a tais vivências (computadores, DVD players, projetores). Além desses problemas, vamos ao encontro de outra questão, a falta de formação e preparação do professor (de arte ou de outras disciplinas) quanto ao domínio dos conteúdos do ensino de cinema na escola formal. 


\section{O professor de cinema}

Cursos como as antigas licenciaturas em educação artística, e mesmo as atuais licenciaturas em artes visuais, estudam de forma superficial o cinema, isto quando acontece. Sabemos que um possível motivo desta deficiência acontece pela especificidade da linguagem cinematográfica, que mesmo sendo classificada por alguns teóricos como artes visuais, apesar de suas aproximações com a pintura, com a gravura ou a fotografia, se mostra uma linguagem bastante diferente. Um professor de artes visuais, sem estudos específicos ou uma formação continuada, poderia trazer teorias de composição de imagens ou de semiologia das cores para as aulas de cinema, mas e quanto aos conteúdos de dramaturgia, de mise-en-scène? Para isto, talvez um professor com formação em teatro, contribuiria de forma mais segura. No entanto, este, pela sua formação nos cursos de licenciatura em teatro, não saberia aplicar conhecimentos sobre enquadramento ou direção de fotografia (a iluminação cênica é bastante diferente da iluminação cinematográfica).

Uma outra alternativa seria convidar profissionais de fora da escola para auxiliar os professores nesta empreitada. Artistas, cineastas, produtores, técnicos e pessoas próximas ao fazer cinematográfico e, consequentemente, todos externos à escola, poderiam ser de grande valia em ações de Cinema e Educação na instituição. O teórico Alain Bergala tem uma posição bastante peculiar acerca do assunto:

A arte é por definição um elemento perturbador dentro da instituição. Ela não pode ser concebida pelo aluno sem a experiência do "fazer" e sem o contato com o artista, o profissional, entendido como corpo "estranho" à escola, como elemento felizmente perturbador de seu sistema de valores, de comportamentos e de suas normas relacionais. A arte não deve ser nem a propriedade, nem a reserva de mercado de um professor especialista $(2008$, p.30).

Não sabemos, no entanto, até que ponto a presença de profissionais não licenciados à frente das salas de aula seria benéfica aos alunos, especialmente no Brasil, onde questões de ordem política poderiam exercer influência negativa em tais processos, transformando escolas públicas em cabides de emprego em troca de favores ou posicionamentos políticos. Ou ainda, gerar ocupações com baixíssimas remunerações ou até mesmo, um voluntariado exploratório como acontece em várias partes do país em projetos como o Mais Educação. O programa em questão foi criado 
pelo Ministério da Educação (Portaria interministerial nº17/2007 e Decreto 7.083/10) com intenção de estimular a educação em tempo integral, oferecendo aos alunos no contra turno das disciplinas convencionais, atividades ligadas ao esporte e lazer, cultura e artes, cultura digital, promoção da saúde, comunicação e uso de mídias, atividades ligadas às ciências da natureza e educação econômica. Na prática, vemos que seus instrutores trabalham em cargas horárias e funções em sala de aula, semelhantes a professores concursados ou contratados em troca de uma pequena ajuda de custo para transporte e alimentação.

Por fim, talvez uma opção interessante para conduzir um processo de ensino/aprendizagem em cinema se encontre em um profissional próprio de cinema e ao mesmo tempo, licenciado. Contudo, tais profissionais quase não existem no Brasil. Os que existem são em números inexpressivos, se comparados às necessidades quantitativas das escolas brasileiras. Em nosso país, há apenas um curso de licenciatura em cinema, fundado em 2012, na Universidade Federal Fluminense (UFF). Uma iniciativa, sem dúvida, pioneira e de extrema importância no campo de estudos do Cinema e Educação, mas ainda muito recente. Com isto, se faz necessária uma maior preocupação por parte dos governantes em fomentar iniciativas assim e criar a abertura de outros cursos em outras instituições. Tal ação seria de grande contribuição para que o ensino do cinema se torne uma realidade em nosso país e aconteça de forma permanente e não esporádica, como tem sido.

\section{O ensino do cinema e a BNCC}

As ações do governo sobre o tema em questão, os ensinos de cinema nas escolas, muitas vezes, nos parecem bastante incongruentes. Enquanto temos sanções importantes como a Lei 13.006/2014, a estruturação da recente Base Nacional Comum Curricular (BNCC), na parte referente às artes, não aborda o cinema como uma linguagem específica, estando ele atrelado às outras linguagens. Quanto a isto, a Sociedade Brasileira de Estudos de Cinema e Audiovisual (SOCINE) se posicionou de forma crítica e pertinente:

[...] Dentro do texto preliminar do BNCC o componente curricular ARTE parte de uma grande área chamada linguagens. Dentro desta área as artes foram divididas em quatro grandes eixos: "artes visuais, dança, teatro e música", 
conforme as licenciaturas específicas em arte, desconsiderando a Licenciatura em Cinema e Audiovisual (Resolução do CNE n. 10, de 27 de junho de 2006) e excluindo completamente o cinema como uma arte específica. Foi essa subdivisão que nos trouxe uma primeira preocupação. Junto à todos esses subcomponentes da área de artes nos parece fundamental que esteja também o cinema. Esta atenção e necessidade não existe apenas porque trabalhamos e pesquisamos cinema e estamos atentos aos seus destinos, mas porque o cinema está intensamente presente na escola e na sociedade e, no momento da construção de uma base nacional para o currículo do ensino infantil, médio e fundamental as questões, contribuições e potencias do cinema na escola não podem ser excluídos [...]. Disponível em: http://www2.socine.org.br/2016/03/socine-se-posicionasobre-a-inclusao-do-cinema-e-audiovisual-na-base-nacional-curricularcomum/. Acesso em: 22 mai. 2018.

Na BNCC, o ensino de artes é dividido em quatro eixos como nos PCN (aqui chamados de unidades temáticas), contudo, ela propõe uma quinta unidade temática denominada artes integradas, que "explora as relações e articulações entre as diferentes linguagens e suas práticas, inclusive aquelas possibilitadas pelo uso das novas tecnologias de informação e comunicação" (BRASIL, 2017, p.155). Desta forma, o documento diz que "é importante que o componente curricular Arte leve em conta o diálogo entre essas linguagens, além de possibilitar o contato e reflexão acerca das formas estéticas híbridas, tais como as artes circenses, o cinema e a performance" (ibid., p.154).

\section{Considerações finais}

Independentemente de quaisquer obrigatoriedades da presença do cinema na escola perante as leis que regem a educação brasileira, os professores em suas diversas disciplinas, já utilizam o cinema como recurso para ilustrar os conteúdos de suas aulas. Sabemos que em tais situações o cinema não é visto como epistemologia, ou seja, como um objeto que possui seus próprios conhecimentos, cuja importância de conhecê-los é fundamental para uma aprendizagem dele enquanto linguagem artística. O cinema nesses casos é visto como meio para alcançar determinados objetivos, como um facilitador e um alicerce para a aprendizagem das demais disciplinas (língua portuguesa, história, geografia). Bergala chama esse procedimento de uso instrumentalizado do cinema.

O teórico não se mostra muito a favor de tais apropriações, contudo, sabemos que a sétima arte pode ser uma ferramenta excelente para esses fins. Podemos afirma \begin{tabular}{ll}
\hline BARBOSA, Diogo José de Moraes Lopes; SCHULZE, Guilherme Barbosa. & 296 \\
Ensino de cinema na educação básica: aspectos legais. &
\end{tabular} Revista GEARTE, Porto Alegre, v. 5, n. 2, p. 289-298, maio/ago. 2018.

Disponível em: http://seer.ufrgs.br/gearte 
que uma aula de história se torna muito mais atrativa quando o fato histórico é mostrado por intermédio da imagem cinematográfica, mesmo compreendendo que o que é mostrado é apenas um recorte, o ponto de vista do cineasta. É dessa forma que a formação do professor se torna fundamental na ação de mediar aquilo que é mostrado no filme com a realidade que o aluno precisa conhecer.

De qualquer forma, seja a utilização do cinema como meio, seja como fim, como já afirmamos, ele faz parte do cotidiano das escolas há tempos. Não apenas na disciplina de arte, mas nas diversas outras. E acreditamos que a sua inserção nos ambientes educacionais, não apenas na escola formal, mas nas ONG, fundações, cursos de formação básica, tendem cada vez mais a crescer, haja vista o rápido desenvolvimento das tecnologias digitais (internet) e da popularização de seus instrumentos (computadores, aparelhos de celular). Resta-nos acompanhar essa nova revolução e tentar compreendê-la, justamente para que possamos fazer o melhor uso dela.

\section{Referências}

BARBOSA, Ana Mae (Org.). Inquietações e mudanças no ensino da arte. São Paulo: Cortez, 2008.

BERGALA, Alain. L'hipothèse cinéma. Petit traité de transmission du cinema à l'école et ailleurs. Paris: Petit Bibliothèque des Cahiers du Cinéma, 2006.

BERGALA, Alain. A hipótese-cinema. Rio de Janeiro: Booklink; CINEAD-LISE-FE/UFRJ, 2008.

BRASIL. Decreto no 21.240, de 4 de abril de 1932. Nacionalizar o serviço de censura dos filmes cinematográficos, cria a Taxa Cinematográfica para a educação popular e dá outras providências. Diário Oficial da União, Rio de Janeiro, RJ, 4 abr. 1932.

BRASIL. Lei de Diretrizes e Bases da Educação Nacional: Lei no 13.278. Brasília: 2016.

BRASIL. Lei de Diretrizes e Bases da Educação Nacional: Lei no 30.006. Brasília: 2014.

BRASIL. Lei $\mathrm{n}$ - 13.415, de 16 de fevereiro de 2017. Altera as Leis $\mathrm{n}$ os 9.394 , de 20 de dezembro de 1996, que estabelece as diretrizes e bases da educação nacional, e 11.494, de 20 de junho 2007, que regulamenta o Fundo de Manutenção e Desenvolvimento da Educação Básica e de Valorização dos Profissionais da Educação, a Consolidação das Leis do Trabalho - CLT, aprovada pelo Decreto-Lei № 5.452, de 1을 de maio de 1943, e o Decreto-Lei oㅡ 236, de 28 de fevereiro de 1967; revoga a Lei no11.161, de 5 de agosto de 2005; e institui a Política de Fomento à Implementação de Escolas de Ensino Médio em Tempo Integral.

BRASIL. Secretaria de Educação Fundamental. Parâmetros curriculares nacionais: arte. Brasília: MEC/SEF, 1997.

BRASIL. Ministério da educação. Portaria Normativa Interministerial n. 17, de 24 de abril de 2007. Institui o Programa Mais Educação, que visa fomentar a educação integral de crianças, adolescentes e jovens, por meio do apoio a atividades sócio-educativas no contraturno escolar. Diário Oficial da União, Brasília, DF, 26 abr. 2007. p.5. 
BRASIL. Ministério da educação. Base Nacional Comum Curricular. Terceira versão. Brasília: MEC, 2017.

BRASIL. Decreto oㅜ 7.083, de 27 de janeiro de 2010. Dispõe sobre o Programa Mais Educação. Diário Oficial da União, Brasília, DF, 27 jan. 2010.

BRASIL. Decreto no 8.620 , de 29 de dezembro de 2015. Dispõe sobre a obrigatoriedade de exibição de obras audiovisuais cinematográficas brasileiras. Diário Oficial da União, Brasília, DF, 29 dez. 2015.

DUARTE, Rosália. Cinema \& Educação. Belo Horizonte: Autêntica, 2002.

FERRAZ, Maria Heloisa C. de T.; FUSARI, Maria F. de Resende e. Arte na educação escolar. São Paulo: Cortez. 2010.

FRESQUET, Adriana (Org.). Cinema e educação: a lei 13.006. Reflexões, perspectivas e propostas. Belo horizonte: Universo Produção, 2015.

Sociedade Brasileira de Estudos de Cinema e Audiovisual - SOCINE - Notícias. Disponível em: <http://www2.socine.org.br/2016/03/socine-se-posiciona-sobre-a-inclusao-do-cinema-e-audiovisualna-base-nacional-curricular-comum/>. Acesso em: 22 mai. 2018.

\section{Diogo José de Moraes Lopes Barbosa}

Licenciado em Educação Artística com Habilitação em Artes Cênicas - Universidade Federal de Pernambuco; Especialista em Estudos Cinematográficos - Universidade Católica de Pernambuco. Aluno do Programa de Mestrado em Artes da Universidade Federal da Paraíba. Professor de Artes e Cinema na educação formal e não formal.

Email: diogo_barbosa@hotmail.com

Currículo: http://lattes.cnpq.br/6845530989853825

\section{Guilherme Barbosa Schulze}

Professor do Departamento de Artes Cênicas da Universidade Federal da Paraíba, no Mestrado Profissional em Artes (PROFARTES) e Mestrado Acadêmico em Artes Visuais (UFPB-UFPE), dos cursos de graduação em teatro e dança. Graduado em Música - Universidade Federal da Paraíba; Especialista em Coreografia - Universidade Federal da Bahia, Mestre em Artes - Universidade Estadual de Campinas e PhD em Estudos da Dança - Universidade de Surrey, Inglaterra.

Email: guilherme.schulze@gmail.com

Currículo: http://lattes.cnpq.br/2239717664426193

Recebido em 23 de maio de 2018

Aceito em 20 de julho de 2018 